\title{
Colposcopic evaluation of unhealthy cervix and it's correlation with Papanicolau smear in cervical cancer screening
}

\author{
Vijay Y. Kalyankar*, Bhakti V. Kalyankar, Shriniwas N. Gadappa, Supriya Kute
}

Department of Obstetrics and Gynecology, Government Medical college, Aurangabad, Maharashtra, India

Received: 19 August 2017

Accepted: 16 September 2017

\section{*Correspondence:}

Dr. Vijay Y. Kalyankar,

E-mail: vijukalyankar@rediffmail.com

Copyright: (C) the author(s), publisher and licensee Medip Academy. This is an open-access article distributed under the terms of the Creative Commons Attribution Non-Commercial License, which permits unrestricted non-commercial use, distribution, and reproduction in any medium, provided the original work is properly cited.

\begin{abstract}
Background: In present study colposcopic evaluation of unhealthy cervix was donr and it's correlation with Papanicolau smear in screening of Cancer cervix. Objective of present study was to critically evaluate the sensitivity and specificity of PAP smear with that of Colposcopy in screening of Cancer Cervix in women with unhealthy cervix. Methods: 100 women with clinically unhealthy cervix on naked eye examination and / or abnormal symptoms attending Gynaecology Out patient department in 2 years period were subjected to PAP smear, Colposcopy, biopsies under Colposcopic guidance and findings correlated with Histopatholgy at Govt. Medical college, Aurangabad, Maharashtra. India. The sensitivity and specificity of PAP smear with that of Colposcopy in screening of Cancer Cervix was evaluated.

Results: Both PAP smear and Colposcopy can be reliably used to screen women with premalignant lesions of Cancer cervix.

Conclusions: Colposcopy is a better tool for diagnosis of precursors of Cancer Cervix than PAP Smear and Histopathology of suspected lesion remains the gold standard for final diagnosis.
\end{abstract}

Keywords: Abnormal cervix, Cervical cancer screening, Colposcopy, PAP smear

\section{INTRODUCTION}

Cervical cancer is the commonest malignancy found amongst Indian women and third most common cancer in world. Over 5, 00,000 new cases of invasive cervical cancer are diagnosed annually worldwide. ${ }^{1,2}$

Cancer cervix has a long phase of pre-invasive disease progresses from cellular atypia to various grades of dysplasia or Cervical Intraepithelial Neoplasia before progressing to invasive cancer. Factors like easy accessibility of cervix, propensity of cervical epithelial cells to exfoliate, rapid turnover of epithelial cells, wide spectrum of histopathological changes, prolonged natural history of disease provide best potential for control of progression of disease by screening of population. PAP smear is cytological examination of exfoliated or scrapped cells to detect dysplasia. VIA is visual inspection of cervix using acetic acid, a simple screening method which includes $3-5 \%$ acetic acid application to the cervix and looking for abnormal aceto-white areas suggestive of dysplasia or invasive disease. VILI is visual inspection of cervix using Lugol's iodine, to identify Schiller's light areas to screen pre-invasive disease. VIA and VILI are both easy to perform and interpret, even by the paramedical staff after providing sufficient training.

By Colposcopy, the Squamo-columnar junction and Transformation zone is identified, acetic acid is then used to assess the details of any lesion and labeled according to IFCPC. Abnormal areas can be target biopsied; treatment of lesions can be done preserving fertility. Cytological abnormality can be confirmed by histopathology of Colposcopically biopsied lesions. 
Objective of present study was to critically evaluate the sensitivity and specificity of PAP smear with Colposcopy in screening of Cancer Cervix by correlating with Histopathology in women with unhealthy cervix and abnormal symptoms

\section{METHODS}

This prospective clinical study was done at Govt. medical college, Aurangabad, Maharashtra, India from May 2012 to Nov 2014 on 100 women with unhealthy cervix on naked eye examination and abnormal symptoms.

\section{Inclusion criteria}

- Age- 20-60 years.

- Women with symptoms like white discharge, post coital bleeding, and inter-menstrual bleeding.

- Women with clinically unhealthy cervix (erosion, bulky cervix, bleeding on touch, ulcer, simple leukoplakia, keratinisation).

- Women with PAP smear showing dysplasia.

\section{Exclusion criteria}

- Women with bleeding per vaginum at the time of examination.

- Women with frank invasive cancer.

- Women underwent hysterectomy.

- Pregnant women.

Patients attending Gynecology OPD with complaints like white discharge, backache, pain in abdomen, menstrual disorders, something coming out of vagina, post coital bleeding, post menopausal bleeding were subjected to detail history, clinical and Gynecological examination and naked eye examination of cervix. Inguinal and general Lymphadenopathy, Vulval infections, vaginal inflammation, discharge- it's characters (color, odor, amount, type), cervical inflammation, any growth or bleeding was looked for. PAP smear and Colposcopy was planned in women with abnormal complaints and abnormal cervix on naked eye examination, after consent. PAP smear was not done during menses, during abnormal vaginal bleeding, vaginal douching / sexual intercourse/ antibiotic taken in immediate past. On PAP smear, the Bethesda classification system was used for cytological grading.

Then the women were subjected to Colposcopy examination-machine details as ASCON model AC-32000SN with green filter with ELMOCCD, TV camera and CTV display, focal length $250 \mathrm{~mm}$ and magnification $7.5 \mathrm{X}-10 \mathrm{X}$ and working distance of $25 \mathrm{~cm}$. If complete transformation zone was not visualized, Colposcopy was termed as "Unsatisfactory". The green filter was also used to study vessels. Acetic acid (5\%) and Lugol's iodine were used. Abnormal Colposcopy findings like aceto-white area and abnormal iodine staining areas were analyzed by Modified Reid's index.
Cervix biopsy under intramuscular sedation and para cervical block with $1 \%$ Lignocaine injection was done in whom either PAP smear or Colposcopy or both were abnormal. Biopsy was not taken in whom both PAP smear and Colposcopy were normal and women were asked to follow up at 4-6 months interval, till 3 subsequent negative PAP smears were obtained. Histopathology was done by Senior pathologist. Sensitivity, specificity, positive predictive value, negative predictive value of Colposcopy in diagnosing lesions which were likely to be CIN I or CIN II or CIN III was calculated. Modified Reid's index on Colposcopy was validated with histopathology and this validation was compared with previous studies.

\section{Statistical analysis}

Formulae used for calculation of efficacy

- $\quad$ Sensitivity $=\mathrm{TP} / \mathrm{TP}+\mathrm{FN}$.

- $\quad$ Specificity $=\mathrm{TN} / \mathrm{TN}+\mathrm{FP}$.

- $\quad$ Positive predictive value $=\mathrm{TP} / \mathrm{TP}+\mathrm{FP}$.

- $\quad$ Negative predictive value $=\mathrm{TP} / \mathrm{TP}+\mathrm{FN}$.

- $\quad$ Accuracy $=\mathrm{TP}+\mathrm{TN} /$ Total.

Where, TP is true positive, TN is true negative, $\mathrm{FP}$ is false positive and $\mathrm{FN}$ is false negative.

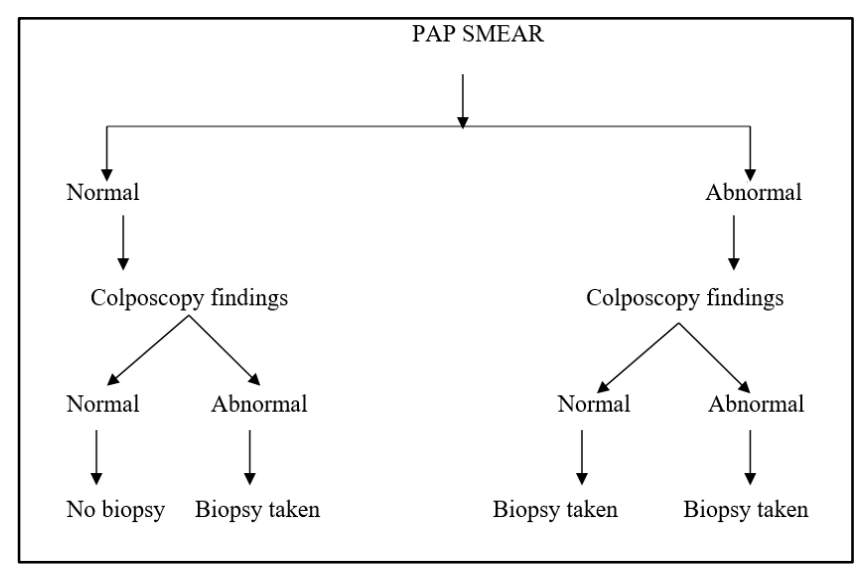

Figure 1: Tree diagram of study protocol.

Unhealthy cervix on naked eye examination.

\section{RESULTS}

31-40 age group 39 cases, 42 cases had Kuppuswamy classification stage IV, 51 were Hindus, 64 were from Rural area and only 8 cases were Para 1.

100 Women with abnormal cervix were subjected to PAP smear and Colposcopy. Unsatisfactory Colposcopy in 2 cases were excluded and rest 98 were included in study. Of these 98, biopsy was taken in 55 cases in whom either PAP smear or Colposcopy or both were abnormal and their correlation studied. 
Table 1: Sociodemographic profile of cases.

\begin{tabular}{|c|c|c|}
\hline Profile & Class & Number \\
\hline \multirow{4}{*}{ Age in years } & $21-30$ & 25 \\
\hline & $31-40$ & 39 \\
\hline & $41-50$ & 23 \\
\hline & $51-60$ & 11 \\
\hline \multirow{5}{*}{$\begin{array}{l}\text { Socio-economic } \\
\text { class } \\
\text { (Kuppuswamy } \\
\text { classification) }\end{array}$} & I & 05 \\
\hline & II & 15 \\
\hline & III & 17 \\
\hline & IV & 42 \\
\hline & V & 19 \\
\hline \multirow{3}{*}{ Religion } & Hindu & 51 \\
\hline & Muslim & 34 \\
\hline & Buddhist & 13 \\
\hline \multirow{2}{*}{ Residence } & Urban & 34 \\
\hline & Rural & 64 \\
\hline \multirow{3}{*}{ Parity } & Para 1 & 08 \\
\hline & Para 2 & 45 \\
\hline & Para 3 and above & 45 \\
\hline
\end{tabular}

White discharge was the most common (56.12\%) symptom followed by pain in Abdomen (16.32\%) and Backace (14.28\%).

Table 2: Distribution of cases according presenting symptoms.

\begin{tabular}{|lll|}
\hline Presenting symptoms & No. of cases & $\%$ \\
\hline White discharge & 55 & 56.12 \\
\hline Backache & 14 & 14.28 \\
\hline Pain in abdomen & 16 & 16.32 \\
\hline Menstrual disorder & 10 & 10.20 \\
\hline Dysparenunia & 07 & 07.14 \\
\hline Postmenopausal bleeding & 06 & 06.12 \\
\hline Post-coital bleeding & 03 & 03.06 \\
\hline
\end{tabular}

Bulky cervix (34.69\%), erosion (30.61\%), both bulky cervix with erosion (13.26\%), ectropy (14.28\%), congested cervix (6.12\%) and $1.02 \%$ of simple leukoplakia made an abnormal cervix to naked eye.
Out of 98 PAP smears, $85.71 \%$ were normal (also included atypia - with no malignancy) and $11.22 \%$ were reported to have LSIL while $3.06 \%$ had HSIL reports. According to International Colposcopy terminology (1990), $57 \%$ were normal, $41 \%$ were abnormal, and $2 \%$ were unsatisfactory.

Amongst 41 patients with abnormal colposcopic findings, $13(23.63 \%)$ were likely to be CIN I, 25 (45.45\%) were likely to be CIN I-II, 3 (5.45\%) were likely to be CIN IIIII according to Modified Reid's Index. On histopathological report, CIN I was found in 15 (27.27\%), CIN II in 21 (38.18\%), CIN III in $5(9.09 \%)$ women. Histopathology was normal in 10 (18.18\%), chronic cervicitis in 2 (3.63\%), endopapillary cervicitis was found in $1(1.81 \%)$ and squamous cell carcinoma in $1(1.81 \%)$ women.

Table 3: Correlation between PAP smear report and colposcopy finding.

\begin{tabular}{|llllll|}
\hline PAP & \multicolumn{2}{l}{ Colposcopic finding } & & \\
smear & CIN & CIN & CIN & Normal & Total \\
\hline Normal & 11 & 16 & 0 & 14 & 41 \\
\hline ASCUS & 0 & 0 & 0 & 0 & 0 \\
\hline LSIL & 2 & 8 & 2 & 0 & 12 \\
\hline HSIL & 0 & 1 & 2 & 0 & 3 \\
\hline $\begin{array}{l}\text { Sq. cell } \\
\text { Ca }\end{array}$ & 0 & 0 & 0 & 0 & 0 \\
\hline Total & 13 & 25 & 4 & 14 & 56 \\
\hline
\end{tabular}

Out of 55, PAP smear reports abnormal were for 14 women, in whom 11 were having LSIL, and 3 were having HSIL, 41 reported normal on PAP smear.

While, colposcopy was abnormal for 41 women and 13 of them were likely to be having CIN-I, 25 were likely to having CIN-II, and 3 were likely to have CIN-III, and 14 were having normal colposcopic findings, according to Modified Reid's index.

Table 4: Correlation between PAP smear report and histopathological report.

\begin{tabular}{|llllllllll|}
\hline PAP smear report & Histopathological report & CIN I & CIN II & CIN III & $\begin{array}{l}\text { Sq. cell Ca } \\
\text { in situ }\end{array}$ & $\begin{array}{l}\text { Endopapillary } \\
\text { cervicitis }\end{array}$ & $\begin{array}{l}\text { Chr. } \\
\text { Cervicitis }\end{array}$ & Normal & Total \\
\hline Normal & 15 & 14 & 0 & 1 & 1 & 2 & 8 & 41 \\
\hline ASCUS & 0 & 0 & 0 & 0 & 0 & 0 & 0 & 0 \\
\hline LSIL & 0 & 7 & 2 & 0 & 0 & 0 & 2 & 11 \\
\hline HSIL & 0 & 0 & 3 & 0 & 0 & 0 & 0 & 3 \\
\hline Sq. cell Ca & 0 & 0 & 0 & 0 & 0 & 0 & 0 & 0 \\
\hline Total & 15 & 21 & 5 & 1 & 1 & 2 & 10 & 55 \\
\hline
\end{tabular}


Amongst 41 women with normal PAP smear ,15 had CINl, 14 had CIN 1l, None of them had ASCUS on PAP smear.
Out of 11 women having LSIL on PAP smear,7 had CIN 11, 2 had CIN 1ll. Out of 3 women having HSIL on PAP smear, all had CIN 111 on histopathology.

Table 5: Correlation between colcoscopic findings and histopathology.

\begin{tabular}{|c|c|c|c|c|c|c|c|c|}
\hline Colposcopic findings & Histop & thologi & I report & & & & & \\
\hline Abnormal & CIN I & CIN II & CIN III & $\begin{array}{l}\text { Sq. cell } \\
\text { Ca }\end{array}$ & $\begin{array}{l}\text { Endopapillary } \\
\text { Cervicitis }\end{array}$ & $\begin{array}{l}\text { Chr. } \\
\text { Cervicitis }\end{array}$ & Normal & Total \\
\hline Likely to be CIN I (0-2) & 13 & 0 & 0 & 0 & 0 & 0 & 0 & 13 \\
\hline Likely to be CIN II (3-4) & 0 & 19 & 3 & 0 & 1 & 2 & 0 & 25 \\
\hline Likely to be CIN III (5-8) & 0 & 0 & 2 & 1 & 0 & 0 & 0 & 3 \\
\hline Normal & 2 & 2 & 0 & 0 & 0 & 0 & 10 & 14 \\
\hline Total & 15 & 21 & 5 & 1 & 1 & 2 & 10 & 55 \\
\hline
\end{tabular}

Table 6: Evaluating validity of colposcopy using modified Reid's Index with histopathology.

\begin{tabular}{|lllll|}
\hline Modified Reid's Index & Over estimation & Accurate estimation & Under estimation & Total \\
\hline Likely to be CIN I (0-2) & 0 & 13 & 2 & 3 \\
\hline Likely to be CIN II (3-4) & 3 & 19 & 3 & 25 \\
\hline Likely to be CIN III (5-8) & 0 & 2 & 8 & 5 \\
\hline Total & 3 & 34 & 35 \\
\hline
\end{tabular}

Table 7: Sensitivity and specificity of PAP smear in diagnosing CIN.

\begin{tabular}{|ll|}
\hline Sensitivity & Percentage \\
\hline Specificity & 26.66 \\
\hline Positive predictive value & 80.00 \\
\hline Negative predictive value & 85.71 \\
\hline Accuracy of PAP & 19.51 \\
\hline
\end{tabular}

Out of 13 women who were likely to be CIN I on colposcopy, all were having CIN I, and in 2 women having normal colposcopic finding were having CINI on histopathology.

Table 8: Sensitivity and specificity of Colposcopy in diagnosing CIN.

\begin{tabular}{|l|l|}
\hline Sensitivity & Percentage \\
\hline Specificity & 90.47 \\
\hline Positive predictive value & 76.92 \\
\hline Negative predictive value & 92.68 \\
\hline Accuracy of colposcopy & 71.42 \\
\hline
\end{tabular}

Out of 25 women who were likely to be CIN I-II on colposcopy, none were having CIN I, 19 were having CIN II, 3 of them were having CIN III and 1 was having endopapillary cervicitis and 2 were having chronic cervicitis. Out of 3 women who were likely to be CIN IIIII on colposcopy, on histopathology1 was having squamous cell carcinoma, 2 were having CIN III
Out of 14 women normal on colposcopy, 10 were normal on histopathology. Out of 45 women 34 were estimated accurately, 3 women were overestimated and 8 were underestimated.

\section{DISCUSSION}

Routine screening with PAP smear has high false negative rates from 1.8 to $20 \%$. Colposcope, has the ability to localize and determine the extent of all lesions not seen on naked eye are detected in single sitting. Colposcopy helps in selecting the site of biopsy, patients for conservative treatment of CIN, follow up of Intraepithelial neoplasia and early invasive carcinoma, evaluation of Adenosis.

The mean age of women in Our study was 36.5 years. This corresponds to $34.5,36$ and 36 in studies done by Pandey et al, Goel et al, Durdi $\mathrm{G}$ et al respectively. ${ }^{3-5}$

The mean parity of women in Our study was 3. This corresponds to 2.7, 2 and 3 in studies done by Goel et al, Durdi $G$ et al and Ashmita D et al respectively. ${ }^{4-6}$

The Indian registries show a significantly lower incidence of cervical cancer in Muslims compared to other religious groups. $^{7}$ Mohanty $\mathrm{J}$ et al had zero Muslims. $^{8}$ Swarnakumari et al had 25\% Muslims and present study had $34.69 \%$ Muslims, 52\% Hindus and $13.26 \%$ others. ${ }^{9}$ Probably, early marriages, low socio-economic status, poor hygiene offset the advantages of Circumcision. Mohanty et al had 55\%, Ashmita D in had $46.11 \%$ and 
present study had $62.29 \%$ women from low socioeconomic class. ${ }^{6,8}$ Thus, low income favors increase in cervical cancer. The present study had $56.12 \%$ women with white discharge for more than 1 year and $7.14 \%$ with post coital bleeding. Durdi $\mathrm{G}$ et al in $66 \%$ and $5.1 \%$ while Bharani Bharati et al in had $52 \%$ and $6.28 \%$ respectively for the same..$^{5,10}$

In study by Denny L et al, $84.8 \%$ of PAP smears were normal, 7\% were ASCUS, 5.3\% reports LSIL<2.7\% reports HSIL and $0.1 \%$ had invasive carcinoma. ${ }^{11}$ In study by Shastri SS et al, $95.4 \%$ were normal, $0 \%$ had ASCUS, $0.026 \%$ reported LSIL, $0.01 \%$ as HSIL and $0.0007 \%$ had Invasive carcinoma. ${ }^{12}$ In study by Durdi G et al, $35 \%$ were normal, $29.2 \%$ had ASCUS, $23.8 \%$ reported LSIL, $12 \%$ as HSIL and $0.0 \%$ had Invasive carcinoma. ${ }^{5}$ In the present study, $85.71 \%$ were normal, $0 \%$ had ASCUS, $11.22 \%$ reported LSIL, $12 \%$ as HSIL and $0.0 \%$ had invasive carcinoma. Differences in PAP smear reporting in different studies are due to differences in sampling, staining and fixation techniques and observer's errors.

We had "unsatisfactory colposcopy" in present study to 2\%. This was $7.4 \%$ in Bharani Bharati et al, 5.22\% in Durdi $\mathrm{G}$ et al, and $2 \%$ in Pravin $\mathrm{S}$ et al in respectively. ${ }^{5,9,10}$

Bharati B et al had 22.2\%, Sankarnarayan R et al had $16.1 \%$, Sherwani RK et al (12) had $31.1 \%$ while Present study had $42 \%$, respectively as "abnormal colposcopic" findings. ${ }^{10,3,14}$ The percentage of Vascular abnormalities were respectively $12.8 \%, 11.1 \%$ and $7.14 \%$ in studies done by Arora R et al, Sherwani RK et al and in Present study. ${ }^{13,15}$

Table 9: Distribution of cases according to histopathological findings.

\begin{tabular}{|c|c|c|c|c|c|c|}
\hline Name of study & Normal & Benign & CIN I & CIN II & CIN III & $\begin{array}{l}\text { Invasive } \\
\text { carcinoma }\end{array}$ \\
\hline Zarchi $\mathrm{M}$ et $\mathrm{al}^{16}$ & $193(90.6 \%)$ & - & $16(6.5 \%)$ & $2(0.9 \%)$ & - & $2(0.9 \%)$ \\
\hline Pimpale SA et al ${ }^{17}$ & & $1576(85.14 \%)$ & $113(4.32 \%)$ & $56(3.02 \%)$ & $50(2.7 \%)$ & $56(3.02 \%)$ \\
\hline Durdi GS et $\mathrm{al}^{5}$ & - & $167(66 \%)$ & $60(23.6 \%)$ & $8(3 \%)$ & $19(7.4 \%)$ & \\
\hline Present study & $10(18.18 \%)$ & $3(5.45 \%)$ & $15(27.27 \%)$ & $21(38.18 \%)$ & $5(9.09 \%)$ & $1(1.81 \%)$ \\
\hline
\end{tabular}

Table 10: Correlation between PAP smear report and colposcopy finding.

\begin{tabular}{|lllllll|}
\hline \multirow{2}{*}{ Pap smear } & \multicolumn{4}{ll}{ Colposcopic finding by Modified Reid's Index } \\
& Asmita D et al & \multicolumn{5}{l|}{ Present study } \\
\hline Normal/NLIM & $0-2$ & $3-6$ & $>6$ & $0-2$ & $3-6$ & $>6$ \\
\hline ASCUS & 27.9 & 51.2 & 20.9 & 26.82 & 39.02 & 0 \\
\hline LSIL & 00 & 100 & 00 & 00 & 00 & 00 \\
\hline HSIL & 00 & 66.7 & 2.3 & 18.18 & 72.72 & 18.18 \\
\hline Unsatisfactory smear & 00 & 66.7 & 00 & 00 & 33.33 & 66.66 \\
\hline
\end{tabular}

Percentage of LSIL is more in present study.

Table 11: Correlation between PAP smear report and histopathology report.

\begin{tabular}{|llllllllll|}
\hline \multirow{2}{*}{$\begin{array}{l}\text { PAP } \\
\text { smear } \\
\text { report }\end{array}$} & Ashmita D & \multicolumn{7}{c|}{ Present study } \\
& Normal & CIN I & CIN II-III & Benign & Normal & CIN I & CIN II-III & Benign & Sq. cell \\
\hline Normal & 23.3 & 4.7 & 0 & 67 & 19.51 & 36 & 34 & 7 & 0.02 \\
\hline ASCUS & 0 & 33 & 0 & 67 & 0 & 0 & 0 & 0 & 0 \\
\hline LSIL & 0 & 0 & 0 & 100 & 18 & 81 & 0 & 0 & 0 \\
\hline HSIL & 0 & 0 & 100 & 0 & 0 & 0 & 100 & 0 & 0 \\
\hline Sq. cell Ca & - & - & - & - & 0 & 0 & 0 & 0 & 0 \\
\hline
\end{tabular}

In Zarchi MK et al study out of 47 patients having abnormal colposcopic findings, $15 \%$ were CIN I, $6.5 \%$ CIN II and $4.15 \%$ were CIN III. ${ }^{16}$ In a study by Pimpale
SA et al out of 1931 patients with abnormal Colposcopy, $35.27 \%$ were CIN I, $8.97 \%$ were CIN II and CIN III. ${ }^{17}$ 
In a study by Durdi GS et al out of 254 patients having abnormal colposcopic findings, $29.8 \%$ were CIN I, $1.9 \%$ CIN II and $7.4 \%$ CIN III. ${ }^{5}$ In present study out of 51 women having abnormal colposcopic findings, $25.63 \%$ were CIN I, $45.45 \%$ were CIN I -CIN II and $5.45 \%$ were CIN II-CIN III.

Sampling variation and difference in inclusion criteria may produce disparity in Colposcopic findings of different studies.

So, the percentage of LSIL and HSIL that reported CIN on histopathology is more in Present study. The differences in the Observations of two studies is due to differences in cytological reporting of smears and subjective variations in Colposcopy findings in both above tables. In Durdi $\mathrm{G}$ et al study, out of 254 cases 51 (20.1\%) were CIN I, 4 (1.5\%) CIN II and 19 (7.4\%) CIN III by both Colposcopy and Histology. ${ }^{5}$

In Present study, out of 55 cases 15 (27.27\%) were CIN I, 19 (34.54\%) CIN II and 5 (9.09\%) were CIN III by both Colposcopy and Histology respectively.

Sampling variation may lead to disparity between results of different studies.

Table 12: Incidence of accurate, under and over estimation in different studies.

\begin{tabular}{|lllll|}
\hline & Estimation & CIN I & CIN II & CIN III \\
\hline \multirow{4}{*}{$\begin{array}{l}\text { Durdi G } \\
\text { et al }\end{array}$} & Accurate & $\begin{array}{l}51 \\
(67.1 \%)\end{array}$ & $\begin{array}{l}4 \\
(80 \%)\end{array}$ & $\begin{array}{l}19 \\
(100 \%)\end{array}$ \\
& Over & $\begin{array}{l}22 \\
(29 \%)\end{array}$ & -- & -- \\
\cline { 2 - 5 } & Under & $\begin{array}{l}3 \\
(3.9 \%)\end{array}$ & $\begin{array}{l}1 \\
(20 \%)\end{array}$ & -- \\
\hline & Accurate & 13 & 19 & 3 \\
& $(86.66 \%)$ & $(76 \%)$ & $(60 \%)$ \\
\hline \multirow{2}{*}{$\begin{array}{l}\text { Present } \\
\text { study }\end{array}$} & Over & 00 & 3 & 00 \\
& Under & 2 & 3 & 2 \\
& & $(13.33 \%)$ & $(12 \%)$ & $(40 \%)$ \\
\hline
\end{tabular}

In present study, no case was overestimated by Colposcopy and Results were comparable with other studies.

\section{Statistical parameters for PAP smear in different studies}

Basu and Sankarnarayan et al gave $29.5 \%$ sensitivity and $92.3 \%$ specificity. ${ }^{18}$ Goel A gave $50 \%$ sensitivity and 97\% specificity. ${ }^{4}$ Similarly, Surendra $\mathrm{S}$ et al gave $57.4 \%$ Sensitivity and $98.6 \%$ Specificity. ${ }^{12}$ Sherwani RK et al had $53.7 \%$ and $50 \%$, Ghosh P et al had $52.6 \%$ and $99.1 \%$, while present study had $26.66 \%$ and $80 \%$ Specificity respectively. ${ }^{13,19}$ Thus, we found them lower than previous studies. The differences in sensitivity and specificity of different studies is due to differences in laboratory values and availability of trained personnel. Positive predictive value is $85.71 \%$ while negative predictive value is $19.51 \%$ and accuracy is $36.36 \%$.

\section{Statistical parameters for colposcopy in different studies}

In the study of Ghosh $\mathrm{P}$ et al, in sensitivity and specificity for coploscopy was $84.2 \%$ and $97.6 \% .{ }^{19}$ while in study of Durdi $\mathrm{G}$ et al, these are $88.5 \%$ and $86.2 \%$ respectively. ${ }^{5}$ Present study had $90.47 \%$ and $76.92 \%$ specificity respectively and are comparable to previous studies. Positive predictive value is $92.68 \%$ while negative predictive value is $71.42 \%$ and accuracy is $82.27 \%$.

\section{CONCLUSION}

Both PAP smear and colposcopy can be used reliably to screen women having abnormal symptoms for diagnosing premalignant lesions. Critical evaluation of the statistical analysis says that colposcopy can be used as a better tool than PAP smear for diagnosis of precursors of carcinoma of cervix. However, the accuracy of colposcopy is dependent on the training, expertise and skill of the Operator with emphasizes proper training, certification and experience of Colposcopist.

Colposcopy eliminates the need for repeated follow up as in PAP smear which has low sensitivity. As the number of cases studied is less, more cases should be studied for better conclusions. Histo-pathology of suspected lesion remains gold standard for final diagnosis of precancerous lesions, in view of the false positive and false negative cases in this study.

\section{Funding: No funding sources}

Conflict of interest: None declared

Ethical approval: The study was approved by the Institutional Ethics Committee

\section{REFERENCES}

1. Ferlay J, Shin HR, Bray F, Forman D, Mathers C, Parkin DM. Estimates of worldwide burden of cancer in 2008: GLOBCAN 2008. Int $\mathrm{J}$ Cancer. 2010;127:2893-917.

2. World health organization. Comprehensive cervical cancer control: A guide to essential practice. Geneva: WHO; 2006:13-23.

3. Pandey K, Bhogoliwal A: Cancer cervix- need for mass surveillance program specially in Rural areas. J Obstet Gynecol India. 2005;55(5):436-9.

4. Goel A, Gandhi G, Batra S, Bhambani S, Zutshi V, Sachdeva P. Visual inspection of the cervix with acetic acid for cervical Intraepithelial lesions. Dept of Obstetrics and Gynaecology, Maulan Azad medical college, new Delhi, India. Int J Gynecol Obstet. 2005;88(1):25-30.

5. Durdi GS, Sherigar BY, Dalal AM, Desai BR, Malur PR. Correlation of colposcopy using Reid colposcopic index with histopathology-a prospective 
study. J Turkish-German Gynecol Assoc. 2009;10:205-7.

6. Ashmita D, Shakuntala PN. Comparison and Correlation of PAP Smear, Colposcopy and Histopathology in Symptomatic Women and Suspicious Looking Cervix in a Tertiary Hospital Care Centre. IJHSR. 2013;3(5):50-9.

7. Shanta V, Krishnamurthi S, Gajalakshmi CK, Swaminathan R, Ravichandran K. Epidemiology of cancer of the cervix: global and national perspective. J Indian Med Assoc. 2000 Feb;98(2):49-52.

8. Mohanty J, Mohanty BK. Risk factors in Invasive carcinoma of cervix. J Obstet Gynecol India. 1991:403-6.

9. Parvin S, Kabir N, Lipe YS, Nasreen K, Alam KN. Correlation of pap smear and colposcopic finding of cervix with histopatholgiocal report in a group of patient attending in a tertiary hospital. J Dhaka Med Coll. 2013 Jul 7;22(1):39-44.

10. Bharti B., Satish P. Role of Colposcopy In Evaluation of Lower Female Genital Tract in 175 Symptomatic Women. J Obstet Gynecol India. 2004;54:372.

11. Denny L, Kuhn L, Pollack A, Wainwright H, Wright TC. Evaluation of alternative methods of cervical cancer screening for resource-poor settings. Cancer. 2000 Aug 15;89(4):826-33.

12. Shastri SS, Dinshaw K, Amin G, Goswami S, Patil $\mathrm{S}$, Chinoy $\mathrm{R}$ et al. Concurrent evaluation og Visual cytological and HPV testing as screening methods for the early detection of cervical neoplaisia in Mumbai, India. Bull World Healthy Organ. 2005;83(3):186-94.

13. Sherwani RK, Khan T, Akhtar K, Zeba A, Siddique FA, Rahman K et al. Conventional PAP smear and liquid based cytology for cervical cancer screening-a comparative study. J Cytol. 2007;24(4):167-172.
14. Sankaranarayanan R, Basu P, Wesley RS, Mahe C, Keita N, Mbalawa CC et al. Accuracy of visual screening for cervical neoplasia: Results from an IARC multicentre study in India and Africa. Int $\mathbf{J}$ Cancer. 2004 Jul 20;110(6):907-13.

15. Arora R, Vijaya K, Habeebullah S, Asha O, Colposcopic evaluation of unhealthy cervix. J Obstet Gynecol Ind. 2000;50:102-3.

16. Zarchi MK, Binesh F, Kazemi Z, Teimoori S, Soltani HR, Chiti Z. Value of colposcopy in the early diagnosis of cervical cancer in patients with abnormal pap smears at Shahid Sadoughi hospital, Yazd. Asian Pacific J Cancer Preven. 2011 Jan 1;12(12):3439-41.

17. Pimple SA, Amin G, Goswami S, Shastri SS. Evaluation of colposcopy vs cytology as secondary test to triage women found positive on visual inspection test. Indian J Cancer. 2010 Jul 1;47(3):308.

18. Basu PS, Sankaranarayanan R, Mandal R, Roy C, Das P, Choudhury D et al. Visual inspection with acetic acid and cytology in the early detection of cervical neoplasia in Kolkata, India. Int J Gynecol Cancer. 2003 Sep 1;13(5):626-32.

19. Ghosh P, Gandhi G, Kochhar PK, Zutshi V, Batra S. Visual inspection of cervix with Lugol's iodine for early detection of premalignant \& malignant lesions of cervix. The Indian J Med Res. 2012 Aug;136(2):265.

Cite this article as: Kalyankar VY, Kalyankar BV, Gadappa SN, Kute S. Colposcopic evaluation of unhealthy cervix and it's correlation with Papanicolau smear in cervical cancer screening. Int $\mathbf{J}$ Reprod Contracept Obstet Gynecol 2017;6:4959-65. 